\title{
Analysis of Maternal Mortality in Obstetrics and Anesthesia Resuscitation in 15 Years at Chu Point "G" about 389 Cases Bamako/Mali
}

\author{
I. Kanté1", M. Sima1, A. Coulibaly¹, M. Traoré1, T. Théra1, A. Bocoum², S. Z. Daou ${ }^{3}$, A. Kouma4, \\ S. Fané2 ${ }^{2}$ A. Traoré5, 0. Traore 6 , Y. Traoré2, I. Teguété2, B. Maïga ${ }^{1}$ \\ ${ }^{1}$ Obstetric Gynecology Service of C.H.U Point “G”, Bamako, Mali \\ 2Obstetric Gynecology Service of C.H.U Gabriel TOURE”, Bamako, Mali \\ ${ }^{3}$ Common Reference Health Center Commune II, Bamako, Mali \\ ${ }^{4}$ Obstetric Gynecology Service of C.H.U KATI, Bamako, Mali \\ ${ }^{5}$ Obstetrics Gynecology Service of CHU Hospital DU Mali, Bamako, Mali \\ ${ }^{6}$ Common Reference Health Center Commune V, Bamako, Mali \\ Email: *ibrahimkante197462@gmail.com
}

How to cite this paper: Kanté, I., Sima, M., Coulibaly, A., Traoré, M., Théra, T., Bocoum, A., Daou, S.Z., Kouma, A., Fané, S., Traoré, A., Traore, O., Traoré, Y., Teguété, I. and Maïga, B. (2020) Analysis of Maternal Mortality in Obstetrics and Anesthesia Resuscitation in 15 Years at Chu Point "G" about 389 Cases Bamako/Mali. Open Journal of Obstetrics and Gynecology, 10, 243-253.

https://doi.org/10.4236/ojog.2020.1020021

Received: January 9, 2020

Accepted: February 11, 2020

Published: February 14, 2020

Copyright $\odot 2020$ by author(s) and Scientific Research Publishing Inc. This work is licensed under the Creative Commons Attribution International License (CC BY 4.0).

http://creativecommons.org/licenses/by/4.0/

cC) (i) Open Access

\begin{abstract}
Objective: Analyze the maternal mortality in the two departments of CHU Point "G" in Bamako, because of high maternal mortality rate in our country. Material and Methods: This was an analytical cross-sectional study on maternal deaths from February 19, 2005 to November 19, 2019 for patients admitted in both departments and who died during the pregnancy-puerperal period at CHU Point " $G$ ". All the patients who died outside this pregnancy-puerperal period were not retained. The data were entered and analyzed using SPSS 12.0 software. The statistical test used was that of $\mathrm{Chi}^{2}$, the statistical significance threshold was fixed at 5\%. Results: During our study, we recorded 389 maternal deaths out of 16,033 admissions in 15 years and 18,060 live births during the same period making a maternal mortality ratio of 2153.931 and a frequency of 2.426. At the end of our study, we noted that the frequency of maternal deaths was higher in 2014: 12.9\% (50/389). The maternal death predominantly affected women aged of 20 - 24 with a frequency of $22.4 \%$ (87/389). The multiparity (166/389 making 42.7\%), illiteracy (341/389 making $87.7 \%$ ), the poor evacuation conditions (non-medicalized transport): $263 / 389$ making $67.6 \%$; the evacuation without any evacuation sheet: $259 / 389$ making 66.6\%), poor CPN (Prenatal consultation) quality (undone CPN: 191/389 making 49.1\%) and the poor monitoring of delivery works (no use of partograph in 343/389 making $88.2 \%$ ) were the factors favoring maternal deaths. The main causes of maternal deaths were direct in 231/389 making 59.4\% with hemorrhage in first line: $21.1 \%$ (82/389), infec-
\end{abstract}


tion (61/389 cases making $15.68 \%)$, dystocia: 50 cases making $12.85 \%$ and high blood pressure and complications (38/389 making 9.76\%); indirect in $158 / 389$ cases making $40.6 \%$ (Figures $1-3$ ). The majority of women $65.8 \%$ (256/389) of our patients died in the gynecology and obstetrics department; in the Resuscitation department 73/389 making 18.8\%; in the operating room $43 / 389$ making $11.1 \%$ and the deaths that were observed on arrivals represented $17 / 389$ making $4.4 \%$. In our study, $10.3 \%$ (40/389) of our patients died in the antepartum, $57.1 \%(222 / 389)$ in perpartum, and $32.6 \%(127 / 389)$ in the postpartum (Figure 4). The need not covered in blood transfusion represented $91.5 \%$ the cases either 356/389. Conclusion: The frequency of maternal deaths is very high in our country. Reducing the rate of maternal deaths requires improving the SONU (cares obstetrical and neonatal emergency).

\section{Keywords}

Hemorrhage, High Blood Pressure, Maternal Death, Partographe, Prenatal Consultation

\section{Introduction}

The death of a woman in the pregnancy-puerperal period is still experienced as a tragedy. Expecting a child, giving him birth and hugging him are the wishes of every woman. Pregnancy if it is well carried out, leads to a live birth, and constitutes for women a criterion of social valorization. However, for thousands of women, giving birth is not the cause of exhilarationas it should be, but rather a suffering whose outcome can be fatal. The death of a woman is a terrible loss, despite the silence, not only for the family but also for the community and the whole nation [1].

The level of maternal mortality has become an indicator of the performance of the health care system because the visible part of the interventions that prevent maternal death is completely managed by the health services. However, we must look beyond and consider that the maternal death is the result of a chain of dysfunctions and lack of resources, which depend on the factors situated outside the health care system [2]. At the dawn of the new millennium, in the world which is experiencing an unprecedented economic growth and technological progress, there is still an alarming number of women who die during the pregnancy, deliveries and its outcomes [3]. In 2015, 303,000 women died during the pregnancy-puerperal period, approximately 830 women died every day from preventable causes related to pregnancy and deliveries. The maternal mortality ratio in developing countries in 2015 was 239 per 100,000 births, compared to 12 per 100,000 in developed countries; $99 \%$ of all the maternal deaths occur in developing countries, more than half of them in South Sahara Africa. It is the region in which the maternal mortality ratio is the highest representing 542 per 100,000. [4] In Mali, several efforts have been made in the fight against the maternal 
mortality: The report of mortality linked to pregnancies has decreased between 2001 and 2018 from 582 per 100,000 live births to 373 per 100,000 live births in 2018 [5] [6] [7] [8].

The Sustainable Development Goal (SDG) 5 between 2016 and 2030 is to bring the global maternal mortality rate below 70 per 100,000 live births [3] [4]. Despite that some progresses have been made, the maternal mortality rate remains high in our country, hence this work is to contribute to a decline in the rate of maternal mortality with the objective of analyzing the contributing factors and the causes of maternal mortality in the two departments at CHU Point "G".

\section{Patients and Methods}

This was a cross-sectional analytical study on maternal deaths from February 19, 2005 to November 19, 2019 in the gynecology, obstetrics and anesthesia-resuscitation departments of CHU Point "G". The population we studied consisted of all the pregnant women we received and cared for during the study period. Were retained in our study, all the patients admitted in the gynecology and obstetrics department and who died either in the gynecology and obstetrics department or in the anesthesia and resuscitation department during the pregnancy-puerperal period. We excluded all the living women and those who died outside the pregnancy-puerperal period. The variables we studied were the frequency, age, marital status, occupation, antecedents, prenatal consultation (CPN), the parameters of evacuation, the factors favoring maternal death, the causes of maternal death with as of information collecting sources: an individual survey form, obstetrics admission registers, operation reports, obstetric records/files. The data were entered and analyzed using SPSS 12.0 software. The statistical test used was that of Chi-square, the threshold of statistical significance was set at $5 \%$.

\section{Results}

From February 19, 2005 to November 19, 2019, we recorded 389 maternal deaths out of 16,033 admissions and 18,060 live births making a maternal mortality ratio of 2153.931 and a frequency of 2.426 . The ratio of the maternal mortality in these 15 years was higher in 2007 with 5413.105 (38 maternal deaths and 702 live births). The highest frequency of maternal deaths was recorded in 2014 presenting $12.9 \%$.

The 20 - 24 age group was the most frequent in our sample: $22.4 \%(87 / 389)$ and there was a relationship between the age group and the period of death and the duration of stay in the service with $\mathrm{Khi}^{2}$ respectively: 11.32; $\mathrm{P}<0.05$ and $\mathrm{Khi}^{2}$ : 25; $\mathrm{P}<0.05$ [9] (Table 1). The housewives represented $87.4 \%$ (340/389) of our sample. They were uneducated in $87.7 \%$ (341/389) and were married in $93.3 \%$ (363/389) (Table 2). We found a relationship between marital status and the period of death with Chi-square: 10.16 and $\mathrm{P}<0.05$. The spouses were mainly farmers with $28.3 \%(110 / 389)$ and uneducated in $64.8 \%$ (252/389). In our study, 
Table 1. Cross between age group and period of death.

\begin{tabular}{ccccc}
\hline \multirow{2}{*}{ Age group } & \multicolumn{3}{c}{ Period of death } & \multirow{2}{*}{ Total } \\
\cline { 2 - 4 } & Antepartum & Per partum & Postpartum & \\
\hline 14 to 19 & 14 & 38 & 22 & 74 \\
20 to 24 & 10 & 51 & 26 & 87 \\
25 to 29 & 5 & 49 & 24 & 78 \\
30 to 34 & 6 & 39 & 25 & 70 \\
35 to 39 & 3 & 24 & 25 & 52 \\
40 and more & 2 & 21 & 5 & 28 \\
Total & 40 & 222 & 127 & 389 \\
\hline
\end{tabular}

Khi-deux de Pearson: 18.076; P: 0.04.

Table 2. Statut matrimonial de nos patientes.

\begin{tabular}{rcccc}
\hline Marital status & Effective & Percentage & Percentage valid & Pourcentage cumulative \\
\hline Married & 363 & 93.3 & 93.3 & 93.3 \\
Single & 25 & 6.4 & 6.4 & 99.7 \\
Widow & 1 & 0.3 & 0.3 & 100 \\
Total & 389 & 100 & 100 & \\
\hline
\end{tabular}

$61.7 \%(240 / 389)$ of the patients were evacuated, $20.1 \%$ (78/389) of the patients came by themselves and $18.3 \%$ (71/389) of the patients were referred, there was a strong relationship between the mode of admission and the death service with $\mathrm{Khi}^{2}: 24.90 ; \mathrm{P}<0.001$. In $20.6 \%(80 / 389)$ of the cases, the patients came from outside Bamako. Our patients were evacuated in $66.6 \%$ (259/389) of the cases without any evacuation sheets and in $67.7 \%$ (263/389) of the cases without any medicalized means of evacuation (Ambulances). We found a relation between the means of transport and the period, the service of death with respectively $\mathrm{Khi}^{2}$ : 11.98, P: 0.01 and $\mathrm{Khi}^{2}$ : 6; P: 0.01 (Table 3).

The itinerary from home to CHU-Point G without passing by the CHU GT (Gabriel TOURE) constituted the majority with $27.5 \%$ (107/389) of the cases in our sample and we found a strong relationship between distance and period and death service with Chi-square: 31.052; $\mathrm{P}<0.001$. The time of evacuation was less than or equal to 8 hours representing $96.9 \%$ (377/389) of our sample. Deaths were observed on arrivals in $4.4 \%$ (17/389) of the cases in our study. The inter-reproductive interval was less than 1 year (short) presented 83.3\% (324/389) of our sample and there was a relationship between the inter-reproductive interval and the causes and period of maternal death with respectively Chi-square: 28.52; P: 0.01 and Chi2: 10.19; $\mathrm{P}<0.00$. The pauciparous represented $33.4 \%$ (130/389), the multiparous: $22.1 \%(86 / 389)$ and the large multiparous: $20.6 \%$ (80/389) of our sample. The prenatal consultation was not done in $49.1 \%$ (191/389), 89.89\% (178/198) of the cases were within the standards of WHO 
Table 3. Means of transport crossing and period of death.

\begin{tabular}{cccccc}
\hline \multirow{2}{*}{ Means of Transport } & Period of death & \multicolumn{3}{c}{ Period of death } & \multirow{2}{*}{ Total } \\
\cline { 2 - 5 } & Ambulance & 16 & 58 & 52 & 126 \\
Public Transport & 14 & 117 & 47 & $\mathbf{1 7 8}$ \\
Personal car & 10 & 47 & 28 & $\mathbf{8 5}$ \\
Total & $\mathbf{4 0}$ & $\mathbf{2 2 2}$ & $\mathbf{1 2 7}$ & $\mathbf{3 8 9}$ \\
\hline
\end{tabular}

Khi-deux de Pearson: 11.98; P: 0.01.

(World Health Organization) and the midwives were the authors in $32.4 \%$ (127/389) of the cases.

In our study, we have found a relationship between the prenatal consultation and the death service with Chi-square: 13.27; $\mathrm{P}<0.00$. There was also a relationship between the quality of prenatal consultation and the causes of maternal death with Chi-square: 16.64; $\mathrm{P}<0.05$. The partographs were used for monitoring delivery only in $11.8 \%(46 / 389)$ of the cases, and there was a relationship between the use of partographs during the delivery works and the period, causes, and service of maternal death with Chi-square respectively: 49.97; $\mathrm{P}<0.001$; Chi-square: $42.41 ; \mathrm{P}<0.001$ and Chi-square: 8.59 and $\mathrm{P}<0.05$. The use of oxytocics during the delivery works represented $51.7 \%$ (201/389) of the cases and the protocol for the use of oxytocics was correct only in $13.4 \%(27 / 201)$ of the cases. We noted a relationship between the use of oxytocics and the period, causes, and service of maternal death with respectively Chi-square: 33.65 ; $\mathrm{P}<$ 0.001; Chi-square: 29.23; P: 0.01; Chi-square: 35.78; $\mathrm{P}<0.001$. The active management of the third period of delivery was done in 18\% (70/389) of our sample and there was a relationship between the non-practice of GATPA (Active management of the third stage of childbirth) and the causes of maternal death and postpartum blood loss with Chi-square: 29.65; $\mathrm{P}<0.001$; Chi-square: 50.61; $\mathrm{P}<$ 0.001 . The causes of maternal deaths were direct causes in $59.4 \%$ (231/389) (Figure 1 ) with hemorrhage in first line: $21.1 \%$ (82/389) (Figure 2, Figure 3), infection (61/389 cases making $15.68 \%)$, dystocia: 50 cases making $12.85 \%$ and high blood pressure and complications (38/389 making 9.76\%); indirect in 158/389 cases making $40.6 \%$ (Figures 1-3). In 65.6\% (255/389) of the cases the patients were cared for within 24 hours and there is a relationship between the care times and the maternal death service with Chi-square: 10.08; P: 0.03. The blood transfusion needs were not satisfied in $91.5 \%(356 / 389)$ of the cases. In our study, $10.3 \%$ $(40 / 389)$ of our patients died in the antepartum, 57.1\% (222/389) perpartum, and $32.6 \%(127 / 389)$ in the postpartum (Figure 4). The majority of women (65.8\% (256/389) of our patients died in the gynecology department and obstetrics. The patients died within 2 hours after admission in $99.5 \%(387 / 389)$.

\section{Discussion}

During our study we were confronted with many difficulties between other incomplete files, badly informed, badly archived, registers and lost files. 


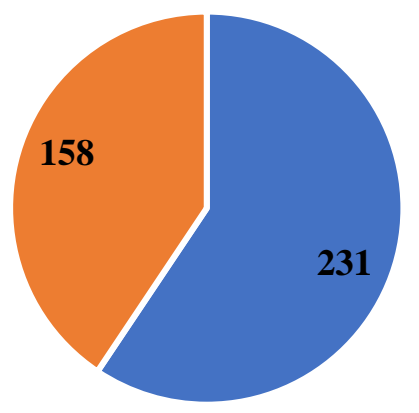

- Direct " Indirect

Figure 1. Causes of maternal deaths.

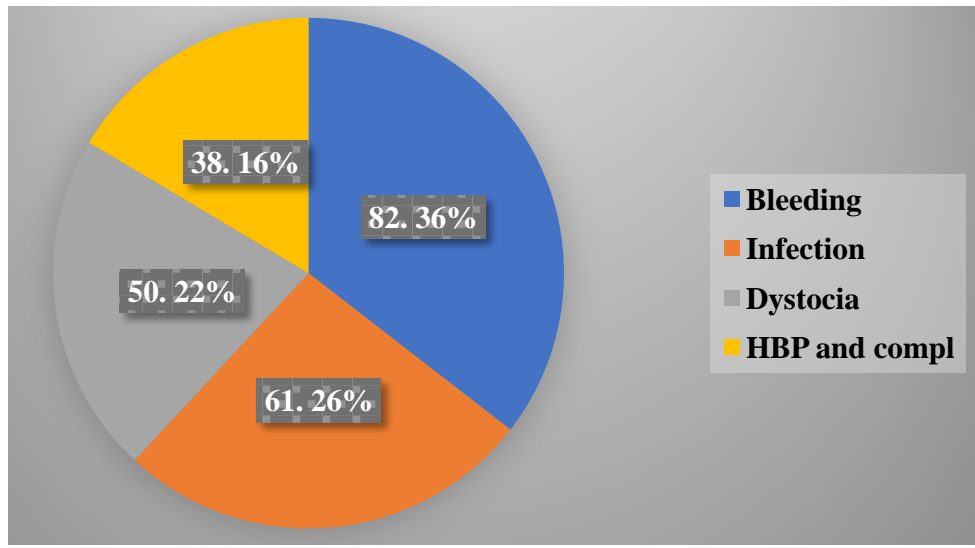

Figure 2. Direct Causes of maternal deaths.

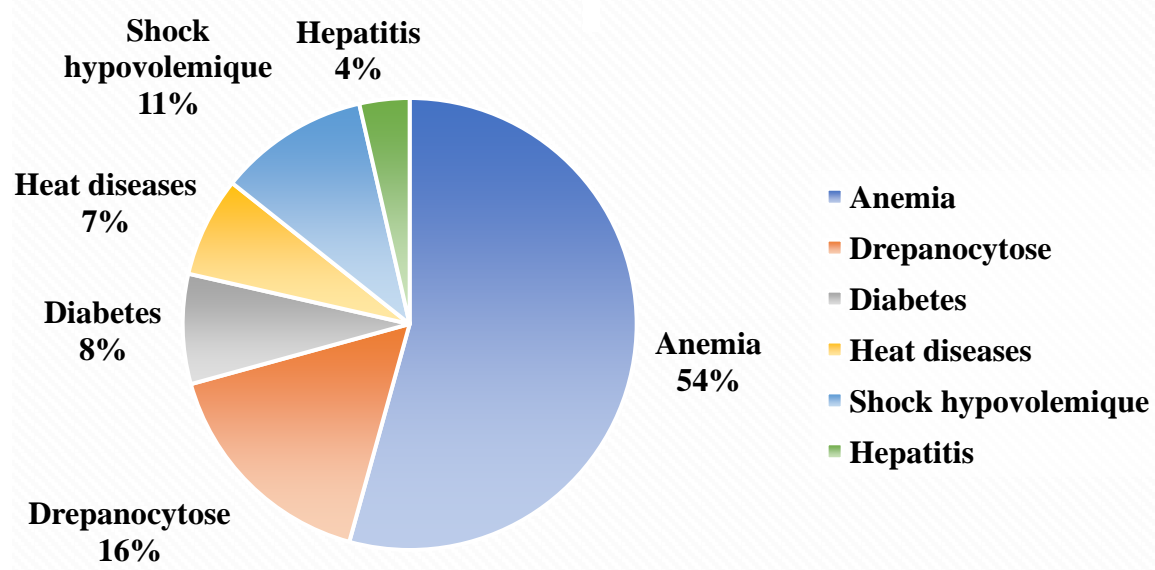

Figure 3. Indirect causes of maternal deaths.

\section{1) The frequency:}

From February 19, 2005 to November 19, 2019, we recorded 389 maternal deaths out of 16,033 admissions and 18,060 live births, making a maternal mortality ratio of 2153.931 and a frequency of 2.426 . The ratio of maternal mortality during these 15 years was higher in 2007 with 5,413,105 (38 maternal deaths and 


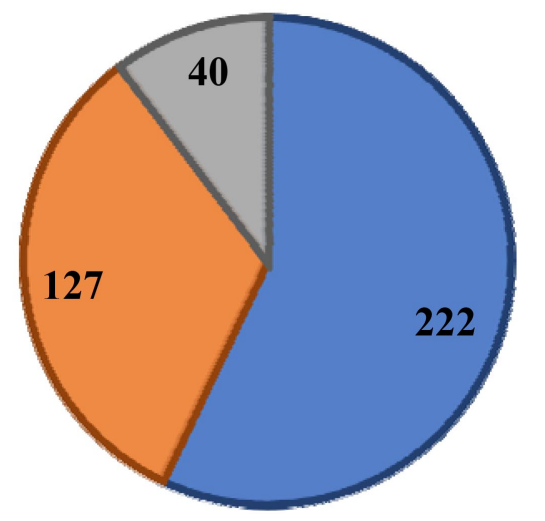

\section{DPerpartum $\square$ Postpartum \\ 口Antépartum}

Figure 4. Period of maternal death.

702 live births). In developing regions, the maternal mortality rate is 450 maternal deaths per 100,000 live births, compared to 9 in developed regions [10] [11]. The highest frequency of maternal deaths was recorded in 2014, 12.9\% in our study.

2) The sociodemographic factors:

In our study, the 20 - 24 age group was the most frequent in our sample: $22.4 \%$ making $87 / 389$ patients, but all the age groups were represented. There was a relationship between the age group and the period of death and the duration of stay in the service with $\mathrm{Khi}^{2}$ respectively: 11.32; $\mathrm{P}<0.05$ and $\mathrm{Khi}^{2}: 25 ; \mathrm{P}<$ 0.05 (Table 1). Koudjou T. andcoll found that the age group $20-24$ was the majority presenting $41.09 \%$ [12]. Boubacar B. and all in Senegal found that the age group 16 - 20 years was the most represented. These figures show that young and very old women are at greater risk of maternal death, so early and late childbearing negatively influences maternal mortality [13]. A study conducted in Nigeria showed that the maternal mortality rate was 7 times higher among women aged of 15 years old than those aged from 20 to 24 [14]. A study carried out in hospitals in Tunisia found that the maternal mortality rate was 33.72 per 100,000 live births and that primiparity, multiparity, unfavorable socio-economic conditions, risky pregnancies and poor follow-up of pregnancy are the risk factors for maternal mortality [15]. In our study, the ethnic group which constituted the majority was Bambara with a frequency of $48.8 \%$ which is the majority ethnic in Mali (Table 4). Housewives represented $87.4 \%$ of our sample; they were uneducated in $87.7 \%$ and were married in $93.3 \%$. We found a relationship between marital status and the period of death with $\mathrm{Khi}^{2}$ : 10.16 and $\mathrm{P}<0.05$. The spouses were farmers in $28.3 \%$ and uneducated in $64.8 \%$. Koudjou T. and all found the same trends compared to the following data: housewives in $95.89 \%$; not in school in 93.15\%; $95.89 \%$ are married [12] Boubacar B. and all found that $85 \%$ of their sample were illiterate and 99\% were married. (11); In RCI Bohoussou and coll [16] and Burkina Faso [17] also found similar figures that is $83 \%$ and $81.60 \%$ respectively [18]. According to Caldwell [19] educated mothers, more than those who are not, tend to use modern health services for both prevention and curative cares in case of illness. 
Table 4. Ethnic of our patients.

\begin{tabular}{ccccc}
\hline Ethnic & Effective & Percentage & Percentage valid & Percentage cumulative \\
\hline Bambara & 190 & $48 / 8$ & 48.8 & 48.8 \\
Soninke & 25 & 6.4 & 6.4 & 55.3 \\
Malinke & 50 & 12.9 & 12.9 & 68.1 \\
Senoufo & 10 & 2.6 & 2.6 & 70.7 \\
Minianka & 8 & 2.1 & 2.1 & 72.8 \\
Bobo & 8 & 2.1 & 2.1 & 74.8 \\
Bozo & 3 & 0.8 & 0.8 & 75.6 \\
Sonrhaï & 12 & 3.1 & 3.1 & 78.7 \\
Peulh & 61 & 15.7 & 15.7 & 94.3 \\
Autres & 9 & 2.3 & 2.3 & 96.7 \\
Dogon & 9 & 2.3 & 2.3 & 99.0 \\
Khassonke & 4 & 1.0 & 1.0 & 100.0 \\
Total & 389 & 100.0 & 100.0 & \\
\hline
\end{tabular}

\section{3) Clinical studies:}

In our study, $61.1 \%$ of patients were evacuated, $20.1 \%$ came by their own and $18.3 \%$ were referred and there was a strong relationship between the mode of admission and the service of death with $\mathrm{Khi}^{2}: 24,90$; $<$ 0.001. In our study, $79.4 \%$ of our patients came from Bamako and $20.6 \%$ outside Bamako. Koudjou $\mathrm{T}$ and all found that $89.04 \%$ of the patients were evacuated [12]. Boubacar B. and all found that $60 \%$ of the women came from rural areas and $40 \%$ from urban areas. This also shows that in rural areas the problem was very important because the factors linked to customs, traditions and delays are more serious [13]. The patients were evacuated in $66.6 \%$ of the cases without any evacuation sheets and $67.7 \%$ of the cases without any medicalized means of evacuation (Ambulances) in our study. We found a relationship between the means of transport and the period, the service of death with respectively $\mathrm{Khi}^{2}: 11.98, \mathrm{P}: 0.01$ and $\mathrm{Khi}^{2}$ : 06, P: 0.01 (Table 3). The itinerary from home to CHU-Point G without passing by CHU GT (Gabriel TOURE) constituted the majority making 27.5\% of the cases in our sample and we found a strong correlation between the distance and the period of death and the death service with $\mathrm{Khi}^{2}: 31.052 ; \mathrm{P}<0.001$.The evacuation time was less than or equal to 8 hours representing $96.9 \%$ of our sample. Maternal Deaths were observed on arrivals in $4.4 \%$ in our study. Koudjou T. and al found that $54.79 \%$ of the women were evacuated by ambulance, $43.21 \%$ without means of transport [12] [20]. The delays were very significant in the fight against maternal mortality. The inter-reproductive interval was less than 1 year (short) represented $83.3 \%$ of the cases in our sample and there was a relationship between the inter-reproductive interval, the causes of maternal death and the periods of maternal death with respectively Chi-square: 28, 52; P: 
0,01 and Chi-square: $10.19 ; \mathrm{P}<0.001$. The pauciparous represented $33.4 \%$; multiparous: $22.1 \%$ and large multiparous: $20.6 \%$ of our sample. The prenatal consultation was not done in $49.1 \%$ of the cases, only $20 \%$ of the cases were within the standards of WHO (World Health Organization) and the midwives were the authors in $32.4 \%$ of the cases. In our study, we found a relationship between the prenatal consultation and the death service with Chi-square: $13.27 ; \mathrm{P}<0.001$. There was a relationship between the quality of the prenatal consultation and the causes of maternal death with Chi-square: 16.64; $\mathrm{P}<0.05$. Koudjou T. and all found that the pauciparous constituted the majority (41.09\%).

The prenatal consultation was not done in $61.64 \%$ and only $17.79 \%$ was of a good quality [12]. According to our study, the partographs were used for delivery monitoring only in $11.8 \%$ of the cases and there was a relationship between the use of the partograph during the delivery works and the period, the causes, and the service of maternal death with Chi-square: 49.97, respectively; $\mathrm{P}<0.001$; Chi-square: 42.41; $\mathrm{P}<0.001$ and Chi-square: 8.59 and $\mathrm{P}<0.05$. The use of oxytocics during deliveries represented $51.7 \%$ of the cases in our sample and the protocol for the use of oxytocics was correct only in $6.9 \%$ of the cases. We found a relationship between the use of oxytocics and the period, causes, and service of maternal death with respectively Chi-square: 33.65; $\mathrm{P}<0.001$; Chi-square: 29.23; P: 0.01; Chi-square: 35.78; $\mathrm{P}<0.001$. The active management of the third period of deliveries was done in $18 \%$ of our sample and there was a relationship between GATPA and the causes of maternal death and postpartum blood loss with $\mathrm{Khi}^{2}$ : 29.65; $\mathrm{P}<0.001$; Chi-square: 50.61; $\mathrm{P}<0.001$. The causes of maternal deaths were direct causes $59.4 \%$ in our study with bleeding in front line: $21.1 \%$ (Figures 1-3). Moussa A. and all found the direct causes of maternal death representing $69.1 \%$ [21]. Koudjou T. and all showed that direct causes represented $68.49 \%$ of the cases and indirect causes: $31.50 \%$; among the direct causes, the hemorrhage constituted the majority with $36.98 \%$ followed by infections (16.46\%) and eclampsia (12.32\%) [12]. The causes of maternal death were dominated by direct causes (80\%): hemorrhage: $40 \%$, pregnancy toxemia: $20 \%$ and infections: $10 \%$. The indirect causes represented $20 \%$ [22]. In worldwide, around $80 \%$ of deaths are due to direct causes. The four main causes are: severe hemorrhages (mostly postpartum hemorrhages), infections (especially sepsis), hypertensive disorders during the pregnancy (usually eclampsia) and dystocia. The complications from unsafe abortions represent $13 \%$ of deaths. Among the indirect causes of maternal death $(20 \%)$, we must retain diseases that complicate the pregnancy or are worsened during this period of life such as malaria, anemia, HIV/AIDS, or cardiovascular diseases [23].

\section{4) Support}

In $65.6 \%$ of the cases in our study, the patients were care for within 24 hours and there is a relationship between the care times and the maternal death service with Chi-square: 10.08 ; P: 0.03 . Moussa A. and all showed that $71.1 \%$ of the patients were cared for/treated before 24 hours [21]. The majority, 65.8\% (256/389) 
of our patients died in the gynecology and obstetrics department; In the study led by Moussa A. and all 76.7\% of patients died in the gynecology department [21]. The patients died within 2 hours after admission in $99.5 \%$ of the cases according to our study. In our study, $10.3 \%$ of our patients died in the antepartum, $57.1 \%$ in perpartum, and $32.6 \%$ in the postpartum. Moussa A. and all found $27.3 \%$ of deaths in the antepartum, $8 \%$ in the perpartum and $64.7 \%$ in the postpartum [21]. The study in Tunisia has shown that all deaths have occurred after delivery, $60 \%$ in the immediate postpartum [22]. The blood transfusion needs were not met in $91.5 \%$ of the cases.

\section{Conclusion}

The maternal mortality remains high in our services and constitutes a major public health problem. It reflects the dysfunction of our health system, namely the problem of qualified personnel, the technical platform of health structures, and the dysfunction of our referral/evacuation system. Reducing the maternal death rate requires improving the SONU.

\section{Conflicts of Interest}

The authors declare no conflicts of interest regarding the publication of this paper.

\section{References}

[1] Akpadza, K., et al. (1994) Maternal Mortality at the Tokoin University Hospital, Lomé 1990 to 1992. French Review of Obstetric Gynecology, 89, 81-85.

[2] WHO (2010) WHO Mortality Database. World Health Organization, Geneva. http://www.who.int/whosis/mort/download/en/index.html

[3] ONU (2010) Statistical Annex: Millennium Development Goals, Targets and Indicators, 2010 ONU, New York, http://mdgs.un.org/unsd/mdg/Resources/Static/Data/2010\%20Stat\%20Annex.pdf

[4] https://www.who.int/reproductivehealth/publications/humanitarian-settings-contra ception/en

[5] Mali Demographic Health Survey I.

[6] World Health Organization (WHO) (2008) Indicators for Assessing Infant and Young Child Feeding Practices. Part I: Definitions. Conclusions of a Consensus Meeting, Washington, DC, 6-8 November 2007. http://whqlibdoc.who.int/publications/2008/9789241596664 eng.pdf

[7] Mali Demographic Health Survey IV

[8] Mali Demographic Health Survey V

[9] Fomulu, J.N., et al. (2009) Maternal Mortality at the Maternity of the University and Hospital Center of Yaoundé, Cameroon: Retrospective Study of 5 Years (2002 to 2006). Health Science, 10, 82-90.

[10] World Health Organization (2007) Maternal Mortality in 2005. Estimates Prepared by WHO, UNICEF, UNFPA and the World Bank. World Health Organization, Geneva. 
[11] Alkema, L., Chou, D., Hogan, D., Zhang, S., Moller, A.B., Gemmill, A., et al. (2016) Global, Regional, and National Levels and Trends in Maternal Mortality between 1990 and 2015, with Scenario-Based Projections to 2030: A Systematic Analysis by the UN Maternal Mortality Estimation Inter-Agency Group. The Lancet, 387, 462-474. https://doi.org/10.1016/S0140-6736(15)00838-7

[12] Koudjou, M., et al. (2008) Study of Maternal Mortality in Gynecology-Obstetrics and Anesthesia-Resuscitation Departments at Point "G": About 73 Cases. Medical Thesis 07/26/2008.

[13] Boubacar, B., et al. (2007-2008) Maternal Mortality in the Department of Bakel: Causes and Favorable Factors Determined by Verbal Autopsy. Master Thesis, Research Institute of Training and Research in Population, Development and Reproductive Health, Cheikh Anta Diop University of Dakar University, Dakar.

[14] Harrison, K.A. (1986) Child Bearing, Health and Social Priorities: A Survey of 22, 774 Consecutive Hospital Births in Zaria, Northern Nigeria. British Journal of $O b$ stetrics and Gynaecology, 92, 1-119.

[15] Mahbouli S., et al. (2003) Maternal Mortality: Epidemiology, Risk Factors and Evitability. About Ten Cases. Volume 31, 1018-1023.

[16] Bohoussou, M.K., et al. (1992) Maternal Mortality in Abidjan in 1988. Médecine d Afrique Noire, 39, 480-484.

[17] Issakha Sombie (2001) Neonatal and Maternal Mortality in Rural Areas in Burkina.

[18] Guyavarch, E. (2007) In Africa, Population Monitoring in the Field to Better Understand Demographic Trends. Population \& Societies, No. 433, 1103-1109.

[19] Caldwell, J. (1979) Education as a Factor in Mortality Decline. An Examination of Nigerian Data. Population Studies, 3, 395-413. https://doi.org/10.2307/2173888

[20] Mbassi, S.M. (2014) Emergency Obstetric Care and Maternal Mortality in Third-Level Maternity Hospitals in Cameroon: Evaluative Approach to an Intervention Aimed at Improving Obstetric Transfer and the Management of Maternal Complications. Pierre et Marie Curie University, Paris. https://tel.archives-ouvertes.fr/tel-01223003

[21] Moussa, A., et al. (2007-2008) Study of Maternal Mortality in the Obstetrics and Gynecology Department of the CHU Gabriel Touré. Doctoral Thesis.

[22] World Health Organization (2005) Let's Give Every Mother and Child a Chance. World Health Report, 68 and 69.

[23] World Health Organization (WHO) (2013) Trends in Maternal Mortality: 1990 to 2013, Estimates from WHO, UNICEF, the United Nations Population Fund (UNFPA), the World Bank and the United Nations Population Division 7. Maternal Health, Fact Sheet 348. 